\title{
Survey of magnetosonic waves and proton ring distributions in the Earth's inner magnetosphere
}

Nigel P. Meredith, ${ }^{1}$ Richard B. Horne, ${ }^{1}$ and Roger R. Anderson ${ }^{2}$

Roger R. Anderson, Department of Physics and Astronomy, University of Iowa, Iowa City, Iowa, IA 52242-1479. (roger-r-anderson@uiowa.edu)

Richard B. Horne and Nigel P. Meredith, British Antarctic Survey, Natural Environment Research Council, Madingley Road, Cambridge, CB3 0ET, England. (r.horne@bas.ac.uk; nmer@bas.ac.uk)

${ }^{1}$ British Antarctic Survey, Natural

Environment Research Council, Cambridge,

England.

${ }^{2}$ Department of Physics and Astronomy, University of Iowa, Iowa City, USA. 


\section{Abstract.}

$4 \quad$ Fast magnetosonic waves can lead to the local acceleration of electrons from ${ }_{5} \sim 10 \mathrm{keV}$ up to a few $\mathrm{MeV}$ on a timescale of 1-2 days and may play an im6 portant role in radiation belt dynamics. Here we present a survey of wave 7 and particle data from the Combined Release and Radiation Effects Satels lite (CRRES) to determine the global morphology of the waves as a func-

tion of magnetic activity, and to investigate the role of proton rings as a po-

tential source mechanism. The intensity of fast magnetosonic waves in the frequency range $0.5 f_{L H R}<f<f_{L H R}$ increases with increasing magnetic activity suggesting they are related to periods of enhanced convection and/or substorm activity. They are observed at most magnetic local times (MLT) outside the plasmapause but are restricted to the dusk sector inside the plasmapause. The MLT distribution of low energy proton rings $\left(E_{R}<30 \mathrm{keV}\right)$ with energies exceeding the Alfvén energy $\left(E_{R}>E_{A}\right)$ required for instability closely matches the distribution of magnetosonic waves on the dusk side, both inside and outside the plasmapause, suggesting that low energy proton rings are a likely source of energy driving the waves. However, intense magnetosonic waves are also observed outside the plasmapause on the dawnside that do not satisfy $\left(E_{R}>E_{A}\right)$. Although proton rings with $E_{R}>$ $30 \mathrm{keV}$ could drive the instabilities, the source of these waves is yet to be properly identified. Since fast magnetosonic waves can accelerate electrons we suggest that they may provide a significant energy transfer process between the ring current and the outer electron radiation belt. 


\section{Introduction}

${ }_{26}$ Relativistic electrons $(E>1 \mathrm{MeV})$ in the Earth's outer radiation belt $(3<L<7)$

27

damage satellites [Wrenn, 1995; Baker, 2001; Wrenn et al., 2002] and may penetrate to low altitudes where they effect the chemistry of the middle atmosphere [e.g., Lastovicka, 1996].

The flux of these so-called killer electrons changes dramatically on a variety of different timescales and covers a range of over five orders of magnitude [Baker and Kanekal, 2007]. This variability is due to acceleration, transport, and loss processes, all of which become enhanced during enhanced geomagnetic activity [e.g., Thorne et al., 2005; Horne et al., $2006]$.

Local acceleration is required to explain the developing peaks in phase space density observed during relativistic electron flux enhancements in the outer radiation belt [Green and Kivelson, 2004; Iles et al., 2006; Chen et al., 2007]. Gyroresonant wave-particle interactions with whistler-mode chorus waves can energize a seed population of electrons with energies of a few hundred $\mathrm{keV}$ up to several $\mathrm{MeV}$ on a timescale of the order of a day [Horne and Thorne, 1998; Summers et al., 1998, 2002, 2007; Meredith et al., 2002a, 2002b, 2003;

Horne et al., 2003, 2005a, 2005b; Shprits et al., 2006] and are consequently considered to be a very important local acceleration mechanism in the inner magnetosphere.

It has recently been suggested that fast magnetosonic waves can lead to local electron acceleration and, in particular, may energize electrons from $\sim 10 \mathrm{keV}$ up to a few $\mathrm{MeV}$ in the outer radiation belt [Horne et al., 2007]. Acceleration by magnetosonic waves, which occurs via electron Landau resonance, may occur on a timescale of 1-2 days which 
46

is similar to that due to whistler mode chorus waves. Thus fast magnetosonic waves could

play an important role in radiation belt dynamics and hence space weather.

Fast magnetosonic waves, also referred to as equatorial noise to show the link with their traditional name [Russel et al., 1970], are a natural, often intense, electromagnetic wave emission observed in the inner magnetosphere near the geomagnetic equator. They were first observed by OGO3 at frequencies between twice the local proton gyrofrequency $\left(f_{c H}\right)$ and half the lower hybrid resonance frequency $\left(f_{L H R}\right)$ and were confined to within $2^{o}$ of the magnetic equator [Russell et al., 1970]. At low frequencies, near the proton gyrofrequency, the spectrum of the waves consists of many spectral lines with different frequency spacings from a few $\mathrm{Hz}$ to a few tens of $\mathrm{Hz}$ [Gurnett, 1976]. The frequency spacing was suggested to occur as result of interactions with ion cyclotron harmonics in a region where the local value for $f_{c H}$ matches the observed spacing. At higher frequencies, both structured [Gurnett, 1976; Santolik et al., 2002] and unstructured [Olsen et al., 1987; Boardsen et al., 1992] emissions have been observed at frequencies just below $f_{L H R}$. Lower frequencies, of the order of several ion gyrofrequencies, tend to be observed more frequently than higher frequencies [e.g., Nemec et al., 2005]. The waves have been observed at radial distances between $2-8 R_{e}$ at all latitudes within $10^{\circ}$ of the magnetic equator [e.g., Perraut et al., 1982; Laakso et al., 1990; Kasahara et al., 1994], primarily in the afternoon and pre-midnight sectors [Perraut et al., 1982; Olsen et al., 1987]. They propagate across the ambient magnetic field $B_{o}$ in the whistler mode with the $k$ vector almost perpendicular to $B_{o}$. They are compressional waves, in that the wave magnetic field lies almost along the ambient magnetic field $B_{o}$ while the wave electric field is elliptically polarized and lies in a plane almost perpendicular to $B_{o}$. In contrast, the wave electric and magnetic 
fields for parallel-propagating whistler mode waves are circularly-polarised in the plane perpendicular to $B_{o}$

More recent data analysis shows that the wave power can be highly variable [André et al., 2002 ] and that the occurrence rate is $60 \%$ near the equator for $3.9<L<5$ [Santolik et al., 2004]. Peak wave intensities occur within $2^{o}$ of the magnetic equator and when the power spectral density is modeled as a Gaussian in frequency the full width half maximum occurs within $3^{\circ}$ of the equator in most cases. Indeed, the central latitudes of fast magnetosonic waves seem to be located exactly at the true geomagnetic equator [Nemec et al., 2006]. Ray tracing shows that propagation outside the plasmapause is limited to latitudes close to the magnetic equator by electron Landau damping on plasmasheet electrons [Horne et al., 2000], although in principle the waves should be able to propagate to higher latitudes inside the plasmapause in regions where the plasma sheet electron flux is very low. The waves propagate both radially and azimuthally around the minimum $B_{o}$ surface [Kasahara et al., 1994].

Simultaneous wave and particle observations, combined with instability calculations, show that the waves can be driven by a proton ring distribution at energies of $\sim 10 \mathrm{keV}$ [Boardsen et al., 1992; Horne et al., 2000]. Proton ring distributions have been observed in association with magnetosonic waves for $L \approx 4$ [Boardsen et al., 1992] and at geostationary orbit [Perraut et al., 1982]. Simulations show that proton ring distributions form during storm times as particles convect and diffuse radially inward and drift around the Earth. The ring forms at the inner edge of the ring current where losses due to charge exchange with neutral hydrogen increase rapidly with decreasing energy [Fok et al., 1995, 1996; Jordanova et al., 1996, 1999]. The ring distribution is also able to reproduce the observed 
at a rate of approximately 1.3 hours per month until the satellite failed on 11 October 1991, when its apogee was at about 1400 MLT. The satellite covered a range of $L$ from $L=1.05$ to $L=\sim 8$ and a range of magnetic latitudes within $\pm 30^{\circ}$ of the magnetic equator, sweeping through the radiation belts approximately 5 times per day, providing good coverage of this important region for almost 15 months.

The wave data used in this study were provided by the Plasma Wave Experiment on board the CRRES spacecraft. This experiment provided measurements of the wave electric fields using a $100 \mathrm{~m}$ tip-to-tip long wire antenna, with a dynamic range covering a factor of at least $10^{5}$ in amplitude [Anderson et al., 1992]. The sweep frequency receiver, used in this study, covered the frequency range from $100 \mathrm{~Hz}$ to $400 \mathrm{kHz}$ in four bands with 32 logarithmically spaced steps per band, the fractional step separation, $\Delta f / f$ being about $6.7 \%$ across the entire frequency range. Band $1(100$ to $810 \mathrm{~Hz})$ was sampled at one step per second with a complete cycle time of $32.768 \mathrm{~s}$. Band $2(810 \mathrm{~Hz}$ to $6.4 \mathrm{kHz})$ was sampled at two steps per second with a complete cycle time of $16.384 \mathrm{~s}$. Band 3 (6.4 to $51.7 \mathrm{kHz})$ and band $4(51.7$ to $400 \mathrm{kHz})$ were each sampled 4 times per second, with complete cycling times of $8.192 \mathrm{~s}$. The nominal bandwidths in bands $1,2,3$, and 4 were $7 \mathrm{~Hz}, 56 \mathrm{~Hz}, 448 \mathrm{~Hz}$, and $3.6 \mathrm{kHz}$, respectively. The electric field detector was thus able to detect waves from below the lower hybrid resonance frequency $\left(f_{L H R}\right)$ to well above the upper hybrid resonance frequency $\left(f_{U H R}\right)$ for a large fraction of each orbit.

The low-energy proton data used in this study were collected by the Low Energy Plasma Analyser (LEPA). This instrument consisted of two electrostatic analyzers with microchannel plate detectors, each with a field of view of $120^{\circ} \times 5^{\circ}$, one measuring electrons and the other positive ions in the energy range $10 \mathrm{eV}<E<30 \mathrm{keV}$ [Hardy et al., 
1993]. The instrument detected the complete pitch angle range from $0^{\circ}$ to $180^{\circ}$ every 30 $\mathrm{S}$ with a resolution of $5.625^{\circ} \times 8^{\circ}$ at 30 energy channels in the range $10 \mathrm{eV}<E<30$ $\mathrm{keV}$. For the purposes of this paper we assume an electron-hydrogen plasma and that the observed ions are protons.

\section{CRRES Database}

In order to perform a statistical analysis of the occurrence of magnetosonic waves, and one source of free energy that can drive the waves unstable, we constructed a database of the wave spectral intensity and proton flux using CRRES data. The wave data were initially corrected for the instrumental background response and smoothed by using a running 3 minute average to take out the beating effects due to differences in the sampling and the spin rate. Spurious data points, data spikes, and periods of instrumental downtime were flagged and ignored in the subsequent statistical analyses. Twelve orbits, during which non-traditional configurations were deployed for testing purposes, were also excluded from the analyses.

Magnetosonic waves generally lie between $f_{c H}$ and $f_{L H R}$. However, since the lowest frequency covered by the sweep frequency receiver is $100 \mathrm{~Hz}$, setting $f_{c H}$ as the lowest frequency for a survey of the wave power would restrict the range of $L$ to very low values $(\leq 1.7)$ as $f \approx f_{c H} \approx 100 \mathrm{~Hz}$ at $L=1.7$. Therefore, wave electric field intensities were determined for the band $0.5 f_{L H R}<f<f_{L H R}$ to provide a balance between including the strongest emissions whilst providing a reasonable coverage in $L$. The intensities in this band, together with the amplitudes from $f_{c e}<f<2 f_{c e}$, the spectral intensities at each frequency of the sweep frequency receiver, and the proton differential number flux at $90^{\circ}$ pitch angle for each energy level of the LEPA instrument, were then rebinned as 
a function of half orbit (outbound and inbound) and $L$ in steps of $0.1 \mathrm{~L}$. The data were recorded together with the universal time (UT), magnetic latitude $\left(\lambda_{m}\right)$, magnetic local time (MLT), substorm and geomagnetic activity indices $A E$ and $K p$, and time spent in each bin with the same resolution.

Since the characteristics of magnetosonic waves may vary according to high and low plasma density the emissions were split into two categories, defined as either inside or outside the plasmapause. Waves in the frequency band $f_{c e}<f<2 f_{c e}$, which may contain contributions from both electrostatic electron cyclotron harmonic (ECH) waves and thermal noise, tend to be excluded from the high density region inside the plasmapause [Meredith et al., 2004]. Therefore we adopt the criterion, based on a previous experimental study using data from the CRRES Plasma Wave Experiment, that the wave amplitude for frequencies in the range $f_{c e}<f<2 f_{c e}$ must be less than $0.0005 \mathrm{mV} \mathrm{m}^{-1}$ for observations to be regarded as inside the plasmapause.

Intense broadband electrostatic noise, extending from $100 \mathrm{~Hz}$ to several $\mathrm{kHz}$, may be present outside the plasmapause during enhanced magnetic activity, especially on the night-side [e.g., Roeder et al., 1991]. These emissions, which could contaminate the observations of the magnetosonic waves, were removed from the database using the following criteria. If the emissions at $1.5 f_{L H R}$ are greater than $2.0 \times 10^{-4} \mathrm{mV}^{2} \mathrm{~m}^{-2} \mathrm{~Hz}^{-1}$ and the emission at $1.5 f_{L H R}$ lies within a factor of 5 of the emission at $0.75 f_{L H R}$ then the emissions were excluded from the database. This condition was only applied to observations outside the plasmapause. 


\section{Identification of magnetosonic waves}

Since calibrated wave magnetic field data in the frequency range above $100 \mathrm{~Hz}$ are not available for CRRES, we have had to identify magnetosonic waves from the wave electric field antenna alone. Since magnetosonic waves are known to be strongest within $2-3^{\circ}$ of the magnetic equator, the wave data were spilt into different latitude ranges, to help identify the waves.

Figure 1 shows the average wave electric field spectral intensities outside the plasmapause for all the CRRES data for (top) equatorial $\left(\left|\lambda_{m}\right|<3^{\circ}\right)$ and (bottom) off-equatorial $\left(5^{\circ}<\left|\lambda_{m}\right|<10^{\circ}\right)$ wave emissions for different levels of geomagnetic activity as measured by $A E *$, where $A E *$ is the maximum value of the $A E$ index in the previous 3 hours. Here and henceforth, average values of a particular quantity are determined by computing the arithmetic mean of the appropriate rebinned CRRES data as a function of the chosen parameters, subject to the prescribed conditions, and subsequently plotted using a logarithmic scale. Near the magnetic equator (top row) there are strong wave emissions below $f_{L H R}$ (dashed line) for all levels of $A E *$ but there is a tendency for wave power to become stronger and extend to lower frequencies and lower $L$ with increasing $A E *$. There is a clear upper frequency cut off to the emissions that follows $f_{L H R}$.

At higher latitudes outside the plasmapause, and for weak magnetic activity (Fig 1, bottom left), strong wave emissions are observed below $f_{L H R}$ but they appear more confined in $L$ than those near the magnetic equator (top left). More generally, emissions below $f_{L H R}$ at high latitudes (bottom panels) tend to be much weaker than those near the magnetic equator (top panels), particularly for medium and high magnetic activity. 
Whistler mode chorus waves are observed at higher frequencies in bands just above and below $0.5 f_{c e}$ (dotted line) and reveal the double-banded nature reported by previous workers [Tsurutani and Smith, 1974]. The power of these waves increases with magnetic activity as has been reported before [e.g., Tsurutani and Smith, 1974, 1977; Meredith et al., 2001, 2003b], but note that chorus detected here is stronger above the magnetic equator than near the equator. This probably reflects the growth and propagation characteristics of the waves [Bortnik et al., 2007a, 2007b]. At higher frequencies ECH waves are observed between the harmonics of $f_{c e}$. These waves are also substorm-dependent [e.g., Meredith et al., 2000] and are closely confined to the magnetic equator due to propagation conditions [e.g., Horne, 1988, 1989].

The average wave electric field spectral intensities inside the plasmasphere are shown in Figure 2 in the same format as Figure 1. Here the most intense emissions are below $f_{L H R}$ near the magnetic equator (top panels). The band of emissions extends to lower frequencies with increasing magnetic activity, $A E *$, but wave power can be very intense for both low and high levels of $A E *$. Note that during the most active conditions (top right) power extends between $3 \leq L \leq 5$. The weaker emissions between $100-800 \mathrm{~Hz}$ with spectral intensities of the order of $5 \times 10^{-5} \mathrm{mV}^{2} \mathrm{~m}^{-2} \mathrm{~Hz}^{-1}$ that do not exhibit a cut-off at $f_{L H R}$ are likely to be plasmaspheric hiss. At higher frequencies just above and below $0.5 f_{c e}$ is interesting to note that there is very little chorus wave power inside the plasmasphere compared to the higher powers observed outside, which suggests that chorus is not easily generated inside the plasmasphere.

The analysis shown in Figures 1 and 2 shows that wave emissions below $f_{L H R}$ near the magnetic equator between $\left|\lambda_{m}\right|<3^{\circ}$ are much stronger than those at higher latitudes 
$5^{\circ}<\left|\lambda_{m}\right|<10^{\circ}$ whether inside or outside the plasmapause, and for each level of magnetic activity as measured by $A E *$. Chorus wave power does not extend down below $f_{L H R}$, but plasmspheric hiss may be present near and above the magnetic equator, and propagation studies show that it can propagate across the magnetic equator to higher latitudes [e.g., Church and Thorne, 1983]. Similarly, impulsive signals originating from lightning which merge into a continuum after multiple reflections inside the plasmasphere [e.g., Bortnik et al., 2003] may also contribute to emissions at and above the magnetic equator, although the main contribution is at frequencies above $2 \mathrm{kHz}$ [Meredith et al., 2006]. However, the rapid increase in wave power within $3^{\circ}$ of the magnetic equator, and the confinement of strong wave power to below $f_{L H R}$, indicates an additional wave emission is present, both inside and outside the plasmapause. It is possible that some of this equatorial wave power is due to electrostatic waves. However, between $f_{c H}$ and $f_{L H R}$ the refractive index surface of the whistler mode branch is closed and the waves are electromagnetic. Electrostatic ion cyclotron waves could exist between the harmonics of $n f_{c H}$, up to and including the lower hybrid resonance frequency, and are analogous to ECH waves between $n f_{c e}$ up to an including the upper hybrid frequency. However, theory shows that these waves should be Landau damped by thermal (1-10 eV) electrons [Ashour Abdalla and Thorne, 1977]. In addition, analysis of equatorial noise near $L=4.5$ using CLUSTER, which has both electric and magnetic wave instruments, has not identified any electrostatic ion-cyclotron waves at the equator as far as we are aware [e.g., Santolik et al., 2002, 2004; Nemec et al., 2005, 2006]. As a result, and since observations by other satellites show that magnetosonic waves are observed very close to the magnetic equator, and propagation studies show that the largest wave growth occurs near the magnetic equator 
where Landau damping by plasmasheet ( 0.1 to few $\mathrm{keV}$ ) electrons is a minimum, for the purposes of this paper we identify the band of waves between $0.5 f_{L H R}<f<f_{L H R}$ for $\left|\lambda_{m}\right|<3^{\circ}$ as fast magnetosonic waves whilst recognizing that there could be a small contribution to the emissions from plasmaspheric hiss and even smaller from lightning generated whistlers. We also note this excludes magnetosonic waves if they occur at higher latitudes. Furthermore, magnetosonic wave power at frequencies below $0.5 f_{L H R}$, where the probability of occurrence maximises [Nemec et al., 2005], will not be captured by this survey. As mentioned above, surveying the frequency band of $0.5 f_{L H R}<f<f_{L H R}$ represents a balance between capturing the intense power of the waves and being able to perform a statistical survey with a reasonable coverage in $L$.

\section{MLT distribution of magnetsonic waves}

The MLT distribution of the average magnetosonic electric field wave intensity for $0.5 f_{L H R}<f<f_{L H R}$ outside the plasmapause is shown in Figure 3 for three levels of $A E *$ (top panels). The plots extend linearly out to $L=8$ with noon at the top and dawn to the right. The sampling distributions are shown by the small inset panels. CRRES has a limited coverage of these wave emissions. Wave power increases with increasing $A E *$, mainly for $L>3$, and strong waves are observed for $L>3$ mainly at dusk between 15:00 - 22:00 MLT and in the post midnight sector between 01:00 - 04:00 MLT. Coverage in $L$ is very limited on the dayside, but strong waves are observed for high magnetic activity near noon between $4<L<5$ and at $2<L<3$. For comparison, waves in the same frequency range at higher latitudes $\left(5^{\circ}<\left|\lambda_{m}\right|<10^{\circ}\right.$ bottom panels) show some tendency to increase with $A E *$, mainly on the dayside, but they remain much weaker than the magnetosonic waves at the equator. 
Inside the plamasphere (Figure 4) magnetosonic waves (top panels) are most enhanced during active conditions on the dusk-side for $L>3$. The lack of coverage on the dawnside in the region $L>4$ during active conditions is due to the fact that the plasmasphere is eroded at these times, with an outer boundary typically inside $L=4$ [Carpenter and Anderson, 1992]. The results suggest either that magnetosonic waves can be generated inside the plasmasphere, or that propagation from outside to inside the plasmasphere is possible at dusk, but not at dawn. For comparison, emissions at higher latitudes in the same frequency range are observed from dawn to dusk inside the plasmapause on the dayside. This rather different MLT distribution of higher latitude emissions inside the plasmasphere suggests that they are more likely to be another type of emission such as plasmaspheric hiss.

\section{Spatial distribution of $16.5 \mathrm{keV}$ protons}

A number of theoretical studies have shown that magnetosonic waves can be generated by a proton ring distribution in velocity space, or more specifically, a ring corresponding to a positive gradient in the perpendicular velocity distribution of the protons which exceeds the local Alfvén speed [e.g., Curtis and Wu, 1979; Sharma and Patel, 1986; Boardsen et al., 1992; Horne et al., 2000]. Wave growth should be sensitive not only to the energy of the ring distribution, but also to the number of resonant protons in the ring. Thus to help understand the wave observations here we present the results of analyzing the proton distribution measured by the LEPA instrument on CRRES. We use the flux at one energy, $16.5 \mathrm{keV}$, as a measure of the particles whose drift trajectories are mainly determined by the convection electric field. 
Figure 5 shows the average proton differential number flux, $J_{\perp}$, for pitch angles of $90^{\circ}$ at $16.5 \mathrm{keV}$. To ensure that the data are statistically significant, the background was first subtracted and the data then binned in $L$ in steps of $0.1 L$ for each half orbit. The data were only included in the subsequent analysis if the number of counts in each $0.1 \mathrm{~L}$ bin exceeded 50. The data were then binned again in MLT, latitude and for inside outside or plasmapause for each activity level. The analysis was restricted to the region $L>2.1$ to exclude contamination from the proton radiation belt. Outside the plasmasphere (top panels) the proton flux increases with $A E *$, and is considerably enhanced during active conditions for $3<L<6$ between 17:00 MLT through midnight to 05:00 MLT. This suggests that proton injection occurs over a broad range of MLT. Weaker enhancements occur in the post-noon MLT sector. Conversely, there is some indication that the proton flux in the pre-noon sector 07:00 - 10:00 MLT actually decreases with increasing $A E *$. Inside the plasmapause (bottom panels) again the flux increases with $A E *$ and is considerably enhanced during active conditions between 14:00 - 23:00 MLT. There is no evidence for increased proton flux near dawn inside the plasmapause during active conditions and the flux there remains low.

\section{Spatial distribution of proton rings}

Proton ring distributions are an important source of free energy that can drive magnetosonic waves. To identify proton rings the proton differential number flux, $J$, was converted to phase space density, $f$, using

$$
f=\frac{J}{p^{2}}
$$


where $p$ is the proton momentum. An examination of the energy dependence of $f$ as a function of half orbit and $L$ showed that positive gradients $\partial f / \partial v_{\perp}>0$ typically exist over $\sim 4(\log )$ energy channels of the LEPA instrument, roughly corresponding to a factor of 2 in energy. A ring distribution was identified according to the criteria that for any given value of $f$ at some energy $E$, the value of $f$ must be higher at the next three or more consecutive energies. This criteria tends to be rather stringent in that it rules out any plateau type distributions that could have been formed as a result of wave particle diffusion, but should provide an unambiguous method of detection. The energy of the ring $E_{R}$, defined to be the energy of the peak in the phase space density, and the Alfvén energy $E_{A}$, were recorded for each distribution where

$$
E_{A}=\frac{1}{2} m_{H} v_{A}^{2}
$$

$m_{H}$ is the proton mass, $v_{A}$ is the Alfvén velocity given by

$$
v_{A}=c \sqrt{\frac{f_{c e} f_{c H}}{f_{p e}^{2}}}=\sqrt{\frac{B_{0}^{2}}{\mu_{0} n_{H} m_{H}}}
$$


20:14 UT (Figure 6b) near 17:00 MLT, consistent with the idea that proton rings are the source of the waves. At 21:00 UT the spacecraft is at $L=5.45$ and the lower hybrid frequency is below the lowest frequency channel of the wave instrument but a proton ring distribution is still present. Note that the waves are particularly strong in a low density region where the plasma frequency drops by a factor of 2 . In this event the proton ring is present for more than 1 hour over a range of $L$ indicating that proton rings can occur over a large region of space and persist for a significant amount of time.

The spatial distribution of proton rings during active conditions outside the plasmapause within $10^{\circ}$ of the magnetic equator is shown in the top left panel of Figure 7. The rings are observed from 12 MLT through midnight to 06 MLT over a range of $L(3<L<7)$. The spatial distribution of the proton rings that satisfy the criteria $E_{R}>E_{A}$ is shown in the upper central panel of Figure 7. Most of the proton rings on the dusk side satisfy the criteria for wave growth whereas the majority of the rings between midnight and dawn do not. The corresponding distribution of magnetosonic waves is shown in the upper right panel of Figure 7 for direct comparison. Although wave coverage is limited, the location of waves on the dusk-side agrees reasonably well with the occurrence of proton ring distributions with $E_{R}>E_{A}$ whereas there is very little agreement between proton rings with $E_{R}>E_{A}$ and waves between midnight and dawn.

The bottom panels of Figure 7 show the results for the case inside the plasmapause. Here, proton rings are observed primarily on the dusk-side, in the region $3<L<7$, from 15 to 22 MLT. The majority of these proton rings satisfy the criteria $E_{R}>E_{A}$ and correspond to the region of enhanced magnetosonic wave power. However, there are almost no proton rings or waves between midnight and dawn. 
energy range of the LEPA instrument $(\mathrm{E}<30 \mathrm{keV})$ the drift paths of protons should be dominated by the convection electric field outside the plasmasphere. The drift paths are usually computed for constant first adiabatic invariant $\mu$, and for reference $\mu=1.4 \mathrm{MeV} / \mathrm{G}$ for $16.5 \mathrm{keV}$ protons at $L=3$ in a dipole magnetic field at the equator. Simulations show that an enhancement in the convection electric field representative of storm times can inject protons with $\mu=3 \mathrm{MeV} / \mathrm{G}$ to as low as $L=3$ over a range of MLT very similar to that observed in Figure 5 [Chen et al., 1993]. As the protons drift to lower $L$ the gradient drift becomes more important and drift trajectories can take the particles through dusk towards the dayside. On the dawn side there is a separatrix between open and closed drift paths that moves closer to the Earth as the convection electric field is increased. The separatrix limits direct convective access to an MLT region that is typically earlier than dawn. Protons outside the separatrix at dawn (i.e., farther away from the Earth at dawn), and similarly outside the separatrix at dusk, follow open drift paths to the dayside. Changes in the separatrix can result in trapping of some protons on closed drift paths and development of the ring current. Therefore the observed increase in the $16.5 \mathrm{keV}$ proton flux outside the plasmasphere is most likely due to direct convective access whereas the reduction in flux observed between dawn and noon is probably due to the lack of direct convective access and decay of the pre-existing proton flux.

The proton flux inside the plasmapause during active conditions has a different MLT distribution that extends from near midnight through dusk to noon. Protons may be observed inside the plasmasphere as a result of time variations in the convection electric field so that the plasmasphere is partially refilled and overlaps the region of proton injection. The data may also include observations of enhanced flux inside plumes which are known 
to develop on the dayside and afternoon. In general, the distribution is consistent with proton injection as discussed above [see also Chen et al., 1994].

After proton injection the formation of proton rings is generally ascribed to losses as a result of slow drift over a select range of energies [Jordanova et al., 1994; Fok et al., 1996]. For positively charged particles the co-rotation drift velocity at dusk is oppositely directed to the gradient and $E \times B$ drift. This leads to a range of energies for which the drift velocity is very slow resulting in a depletion in the proton distribution due to losses as a result of charge exchange and Coulomb collisions. If the losses are sufficiently high then as higher energy protons drift through the same region an energy dependent proton ring distribution may form. In particular, for quiet periods simulations show that there is a range of $\mu<1 \mathrm{MeV} / \mathrm{G}$ for which protons may execute 'banana' shaped drift paths near dusk [Chen et al., 1994] and thus may have an extended dwell time near dusk. This may result in a region where proton rings are more likely to form and may explain the larger number of proton ring distributions observed near dusk and the corresponding increase in wave power. Since the energy of protons executing banana orbits may depend on the strength of the convection electric field this may also determine the energy of the proton rings.

The relationship between magnetosonic waves at dawn and proton ring distributions is more complex. Although proton rings are observed, since $E_{R}<E_{A}$ it appears that low energy protons $(E<30 \mathrm{keV})$ are not the source of the waves seen outside the plasmapause before dawn. There are a number of possibilities. First, a stagnation point resulting in banana orbits can also occur near dawn when the difference between the gradient and co-rotation drifts is approximately equal to the $E \times B$ convection drift. This occurs for 
higher energies than that at dusk [Chen et al., 1994] and thus proton ring distributions may be present at energies above the maximum energy of LEPA. Second, since magnetosonic waves can propagate long distances both radially and azimuthally near the magnetic equator the waves may have propagated from a remote source region. Finally, the waves may be magnetosonic but produced by another process such as nonlinear wave-wave coupling.

Magnetosonic waves are enhanced during active conditions over most local times outside the plasmaspause and on the dusk-side inside the plasmapause. Electrons with energies up to a few hundred $\mathrm{keV}$ can be injected into the outer radiation belt by enhanced stormtime convection electric fields [Baker et al., 1998; Obara et al., 2000]. The motion of these electrons is subsequently dominated by gradient and curvature drifts, leading to closed drift orbits about the Earth on the timescale of the order of an hour or so. During active periods these so-called seed electrons may encounter enhanced magnetosonic waves in the equatorial plane for the bulk of their drift orbits. This could include exposure to magnetosonic waves both inside and outside the plasmapause. Since magnetosonic waves can energize electrons both inside and outside the plasmapause [Horne et al., 2007] our observations suggest that they could play a significant role in the acceleration of a seed population of electrons to relativistic energies. Work is now in progress to quantify the role of these waves in radiation belt dynamics.

Magnetosonic waves in the frequency range $f_{c H}<f<0.5 f_{L H R}$, where the probability of occurrence maximises [Nemec et al., 2005], are excluded from the survey due to the $100 \mathrm{~Hz}$ low frequency limit of the CRRES Plasma Wave Experiment combined with the requirement of reasonable coverage in $L$. The interaction of the waves with proton ring distributions could be quite strong, if not stronger, in this frequency range [e.g., Perraut 
et al., 1982; Laakso et al., 1990, Horne et al., 2000] suggesting that the observed proton rings may also be a source of waves at lower frequencies. Future statistical surveys, using instrumentation that extends to lower frequencies, are required to study the spatial distribution of these waves.

\section{Conclusions}

We have performed a statistical analysis of fast magnetosonic waves and the occurrence of proton ring distributions using wave and particle data from the CRRES spacecraft. Due to the restricted frequency coverage the wave survey was confined to waves with frequencies in the range $0.5 f_{L H R}<f<f_{L H R}$. The main conclusions of this study are

1. The average intensity of fast magnetosonic waves increases with increasing $A E *$, suggesting that they are related to periods of enhanced convective electric field and or substorms.

2. Over the range of $L$ covered by the wave survey $2.5 \leq L \leq 4.5$ intense emissions are observed at most local times outside the plasmapause, but are restricted to the dusk-side inside the plasmapause. The most intense waves generally occur near $L=3-4$.

3. The MLT distribution of low energy proton rings, $E_{R}<30 \mathrm{keV}$ with energies greater than the Alfvén energy $E_{R}>E_{A}$ closely matches the MLT distribution of magnetosonic waves inside the plasmapause, and outside the plasmapause on the dusk side, and suggests that proton ring distributions are a likely source of energy driving the waves. We suggest that 'banana' type drift orbits near dusk, which result in long dwell times, and losses are important for producing proton ring distributions and hence magnetosonic waves near dusk. 
4. Proton ring distributions and intense magnetosonic waves are found outside the plasmapause between midnight and dawn which do not satisfy the condition $E_{R}>E_{A}$ for instability due to the high Alfvén speed in that region. Although proton rings at energies $>30 \mathrm{keV}$ could drive the instabilities the source of these waves is yet to be properly identified.

Since magnetosonic waves are generated by protons and can cause electron acceleration up to $\sim \mathrm{MeV}$ energies inside the radiation belts [Horne et al., 2007] they are likely to provide an important energy transfer process between the ring current and the outer electron radiation belt.

Acknowledgments. We thank the NSSDC Omniweb for providing the $A E$ indices used in this paper. This work was supported by the Natural Environment Research Council.

\section{References}

Anderson, R. R., D. A. Gurnett, and D. L. Odem (1992), CRRES plasma wave experiment, J. Spacecr. Rockets, 29, 570-573.

André, R., F. Lefeuvre, F. Simonet, and U. S. Inan (2002), A first approach to model the low-frequency wave activity in the plasmasphere, Ann. Geophys, 20, 981-996.

Ashour-Abdalla, M., and R. M. Thorne (1977), The importance of electrostatic ioncyclotron instability for quiet-time proton auroral precipitation, Geophys. Res. Lett., $4,45-48$

Baker, D. N. (2001), Satellite anomalies due to space storms, in Space Storms and Space Weather Hazards, edited by I. A. Daglis, 251-284, Springer, New York. 
Baker, D. N., X. Li, J. B. Blake, and S. G. Kanekal (1998), Strong electron acceleration in the Earth's magnetosphere, Adv. Space Res., 21, 609-613.

Baker, D. N., and S. G. Kanekal (2007), Solar cycle changes, geomagnetic variations and energetic particle properties in the inner magnetosphere, J. Atmos. Sol. Terr. Phys., in press.

Boardsen, S. A., D. L. Gallagher, D. A. Gurnett, W. K. Petersen, and J. L. Green (1992), Funnel-shaped low-frequency equatorial waves, J. Geophys. Res., 97, 14,967-14,976.

Bortnik, J., U. S. Inan, and T. F. Bell (2003), Energy distribution and lifetime of magnetospherically reflecting whistlers in the plasmasphere, J. Geophys. Res., 108, 1199, doi:10.1029/2002JA009316.

Bortnik, J., R. M. Thorne, and N. P. Meredith (2007), Modeling the propagation characteristics of chorus using CRRES suprathermal electron fluxes, J. Geophys. Res., 112, A08204, doi:10.1029/2006JA012237.

Bortnik, J., R. M. Thorne, N. P. Meredith, and O. Santolik (2007), Ray tracing of penetrating chorus and its implications for the radiation belts, Geophys. Res. Lett., 34, L15109, doi:10.1029/2007GL030040.

Carpenter, D. L., and R. R. Anderson (1992), An ISEE/Whistler model of equatorial electron density in the magnetosphere, J. Geophys. Res., 97, 1097-1108.

Chen, M. W., M. Schulz, L. R. Lyons, and D. J. Gorney (1993), Stormtime transport of ring current and radiation belt ions, J. Geophys. Res., 98, 3835-3849.

Chen, M. W., L. R. Lyons, and M. Schulz (1994), Simulations of phase space distributions of storm time proton ring current, J. Geophys. Res., 99, 5745-5759. 
Chen, Y., G. D. Reeves, and R. H. W. Friedel (2007), The energization of relativistic electrons in the outer Van Allen radiation belt, Nature Physics, 3, 614-617.

Church, S. R., and R. M. Thorne (1983), On the origin of plasmaspheric hiss: Ray path integrated amplification, J. Geophys. Res., 88, 7941-7957.

Curtis, S. A., and C. S. Wu (1979), Gyroharmonic emissions induced by energetic ions in the equatorial plasmasphere, J. Geophys. Res., 84, 2597-2607.

Fok, M.-C., T. E. Moore, J. U. Kozyra, G. C. Ho, and D. C. Hamilton (1995), Threedimensional ring current decay model, J. Geophys. Res., 100, 9619-9632.

Fok, M.-C., T. E. Moore, and M. E. Greenspan (1996), Ring current development during storm main phase, J. Geophys. Res., 101, 15,311-15,322.

Green, J. C., and M. G. Kivelson (2004), Relativistic electrons in the outer radiation belt: Differentiating between acceleration mechanisms, J. Geophys. Res., 109, A03213, doi:10.1029/2003JA010153.

Gurnett, D. A. (1976), Plasma wave interactions with energetic ions near the magnetic equator, J. Geophys. Res., 81, 27650-2770.

Hardy, D. A., D. M. Walton, A. D. Johnstone, M. F. Smith, M. P. Gough, A. Huber, J. Pantazis, and R. Burkhardt (1993), The low energy plasma analyser, IEEE Trans. Nucl. Sci., 40 (2), 246-251.

Horne, R. B. (1988), Ray tracing of electrostatic waves in a hot plasma and its application to the generation of terrestrial myriametric radiation, Geophys. Res. Lett., 15, 553-556.

Horne, R. B. (1989), Path-integrated growth of electrostatic waves: The generation of terrestrial myriametric radiation, J. Geophys. Res., 94, 8895-8909. 
Horne, R. B., and R. M. Thorne (1998), Potential waves for relativistic electron scattering and stochastic acceleration during magnetic storms, Geophys. Res. Lett., 25, 3011-3014.

Horne, R. B., G. V. H. Wheeler, and C. K. St. Alleyne (2000), Proton and electron heating by radially propagating fast magnetosonic waves, J. Geophys. Res., 105, 27,597-27,610.

Horne, R. B., S. A. Glauert, and R. M. Thorne (2003), Resonant diffusion of radiation belt electrons by whistler-mode chorus, Geophys. Res. Lett., 30 (9), 1493, doi:10.1029/2003GL016963.

Horne, R. B., R. M. Thorne, S. A. Glauert, J. M. Albert, N. P. Meredith, and R. R. Anderson (2005a), Timescale for radiation belt electron acceleration by whistler mode chorus waves, J. Geophys. Res., 110, A03225, doi:10.1029/2004JA010811.

Horne, R. B., R. M. Thorne, Y. Y. Shprits, N. P. Meredith, S. A. Glauert, A. J. Smith, S. G. Kanekal, D. N. Baker, M. J. Engebretson, J. L. Posch, M. Spasojevic, U. S. Inan, J. S. Pickett, and P. M. E. Decreau (2005b), Wave acceleration of electrons in the Van Allen radiation belts, Nature, 437, 227-230, doi:10.1038/nature03939.

Horne, R. B., N. P. Meredith, S. A. Glauert, A. Varotsou, D. Boscher, R. M. Thorne, Y. Y. Shprits, and R. R. Anderson (2006), Mechanisms for the acceleration of radiation belt electrons, in Co-rotating Solar Wind Streams and Recurrent Geomagnetic Activity, in Geophys. Monogr. Ser., 16\%, AGU, Washington, D. C.

Horne, R. B., R. M. Thorne, S. A. Glauert, N. P. Meredith, D. Pokhotelov, and O. Santolk (2007), Electron acceleration in the Van Allen radiation belts by fast magnetosonic waves, Geophys. Res. Lett., 34, L17107, doi:10.1029/2007GL030267.

Iles, R. H. A., N. P. Meredith, A. N. Fazakerley, and R. B. Horne (2006), Phase space density analysis of the outer radiation belt energetic electron dynamics, J. Geophys. 
Res., 111, A03204, doi:10.1029/2005JA011206.

Jordanova, V. K., L. M. Kistler, J. U. Kozyra, G. V. Khazanov, and A. F. Nagy, (1996), Collisional losses of ring current ions, J. Geophys. Res., 101, 111-126.

Jordanova, V. K., C. J. Farrugia, J. M. Quinn, R. B. Torbert, J. E. Borovsky, R. B. Sheldon, and W. K. Peterson (1999), Simulation of off-equatorial ring current ion spectra measured by Polar for a moderate storm at solar minimum, J. Geophys. Res., 104, 429436.

Johnson, M. H., and J. Kierein (1992), Combined Release and Radiation Effects Satellite (CRRES), Spacecraft and mission, J. Spacecr. Rockets, 29, 556-563.

Kasahara, Y., H. Kenmochi, and I. Kimura (1994), Propagation characteristics of the ELF emissions observed by the satellite Akebono in the equatorial plane, Radio Sci., 29, 751-767.

Laakso, H., H. Junginger, A. Roux, R. Schmidt, and C. de. Villedary (1990), Magnetosonic waves above $f_{c H+}$ at geostationary orbit, J. Geophys. Res., 95, 10,609-10,621.

Lastovicka, J. (1996), Effects of geomagnetic storms in the lower ionosphere, middle atmosphere and troposphere, J. Atmos. Terr. Phys., 58 (7),831-843.

Meredith, N. P., R. B. Horne, A. D. Johnstone, and R. R. Anderson (2000), The temporal evolution of electron distributions and associated wave activity following substorm injections in the inner magnetosphere, J. Geophys. Res., 105, 12,907-12,917.

Meredith, N. P., R. B. Horne, and R. R. Anderson (2001), Substorm dependence of chorus amplitudes: Implications for the acceleration of electrons to relativistic energies, J. Geophys. Res., 106, 13,165-13,178, doi:10.1029/2000JA900156. 
Meredith, N.P., R.B. Horne, R.H.A. Iles, R.M. Thorne, D. Heynderickx, and R.R. Anderson (2002a), Outer zone relativistic electron acceleration associated with substormenhanced whistler-mode chorus, J. Geophys. Res., 10\%, doi:10.1029/2001JA900146.

Meredith, N.P., R.B. Horne, D. Summers, R.M. Thorne, R.H.A. Iles, D. Heynderickx, and R.R. Anderson (2002b), Evidence for acceleration of outer zone electrons to relativistic energies by whistler-mode chorus, Ann. Geophys., 20, 967.

Meredith, N. P., M. Cain, R. B. Horne, R. M. Thorne, D. Summers, and R. R. Anderson (2003a), Evidence for chorus-driven electron acceleration to relativistic energies from a survey of geomagnetically-disturbed periods, J. Geophys. Res., 108, 1248, doi: 10.1029/2002JA009764.

Meredith, N. P., R. B. Horne, R. M. Thorne, R. R. Anderson (2003b), Favored regions for chorus-driven electron acceleration to relativistic energies in the Earth's outer radiation belt, Geophys. Res. Lett., 30, 1871, doi:10.1029/2003GL017698.

Meredith, N. P., R. B. Horne, R. M. Thorne, D. Summers, and R. R. Anderson (2004), Substorm dependence of plasmaspheric hiss, J. Geophys. Res., 109, A06209, doi:1029/2004JA010387.

Meredith, N. P., R. B. Horne, M. A. Clilverd, D. Horsfall, R. M. Thorne, and R. R. Anderson (2006), Origins of plasmaspheric hiss, J. Geophys. Res., 111, A09217, doi:10.1029/2006JA011707.

Nemec, F., O. Santolik, K. Gereova, E. Macusova, Y. de Conchy, and N. CornilleauWehrlin (2005), Initial Results of a Survey of Equatorial Noise Emissions Observed by the Cluster Spacecraft, Planetary and Space Sci., 53, 291-298. 
Nemec, F., O. Santolik, K. Gereova, E. Macusova, H. Laakso, Y. de Conchy, M. Maksimovic, and N. Cornilleau-Wehrlin (2006), Equatorial noise: Statistical study of its localization and the derived number density, Adv. Space Res., 3\%, 610-616.

Obara, T., T. Nagatsuma, M. Den, Y. Miypshi, and A. Morioka (2000), Main phase creation of "seed" electrons in the outer radiation belt, Earth Planets Space, 52, 41-47.

Olsen, R. C., S. D. Shawhan, D. L. Gallagher, J. L. Green, C. R. Chappel, and R. R. Anderson (1987), Plasma observations at the Earth's magnetic equator, J. Geophys. Res., 92, 2385-2407.

Perraut, S., A. Roux, P. Robert, R. Gendrin, J. A. Savaud, J. M. Bosqued, G. Kremser, and A. Korth (1982), A systematic study of ULF waves above $f_{H+}$ from GEOS 1 and 2 measurements and their relationship with proton ring distributions, J. Geophys. Res., 87, 6219-6236.

Roeder, J. L., V. Angelopoulos, W. Baumjohann and R. R. Anderson (1991), Observations of correlated broadband elelectrostatic noise and electron cycltron emissions in the plasma sheet, Geophys. Res. Lett., 18, 53-56.

Russell, C. T., R. E. Holzer, and E. J. Smith (1970), OGO 3 observations of ELF noise in the magnetosphere. THe nature of equatorial noise, J. Geophys. Res., 75, 755-768.

Santolik, O., J. S. Pickett, D. A. Gurnett, M. Maksimovic, N. Cornilleau-Wehrlin (2002), Spatiotemporal variability and propagation of equatorial noise observed by Cluster, $J$. Geophys. Res., 107, 1495, doi:10.1029/2001JA009159.

Santolik, O., F. Nemec, K. Gereova, E. Macusova, Y. de Conchy, and N. CornilleauWehrlin (2004), Systematic analysis of equatorial noise below the lower hybrid frequency, Ann. Geophys., 22, 2587-2595. 
Sharma, O. P., and V. L. Patel (1986), Low-frequency electromagnetic waves driven by gyrotropic gyrating ion beams, J. Geophys. Res., 91, 1529-1534.

Shprits, Y. Y., R. M. Thorne, R. B. Horne, M. Cartwright, C. T. Russell, D. Baker, and S. G. Kanekal (2006), Acceleration mechanism responsible for the formation of the new radiation belt during the 2003 Halloween solar storm, Geophys. Res. Lett., 33, L05104, doi:10.1029/2005GL024256.

Summers, D., R. M. Thorne, and F. Xiao (1998), Relativistic theory of wave-particle resonant diffusion with application to electron acceleration in the magnetosphere, $J$. Geophys. Res., 103, 20,487-20,500.

Summers, D., C. Ma, N. P. Meredith, R. B. Horne, R. M. Thorne, D. Heynderickx, and R. R. Anderson (2002), Model of the energization of outer-zone electrons by whistlermode chorus during the October 9, 1990 geomagnetic storm, Geophys. Res. Lett., 29, 10.1029/2002GL016039.

Summers, D., B. Ni, and N. P. Meredith (2007), Timescales for radiation belt electron acceleration and loss due to resonant wave-particle interactions: 2. Evaluation for VLF chorus, ELF hiss, and electromagnetic ion cyclotron waves, J. Geophys. Res., 112, A04207, doi:10.1029/2006JA011993.

Thorne, R. M., R. B. Horne, S. A. Glauert, N. P. Meredith, Y. Y. Shprits, D. Summers, and R. R. Anderson (2005), The influence of wave-particle interactions on relativistic electrons during storms, in Inner Magnetosphere Interactions: New Perspectives From Imaging, in Geophys. Monogr. Ser., vol. 159, edited by J. Burch, M. Schulz, and H. Spence, AGU, Washington D.C., 2005. 
627

628

629

630

631

632

633

634

Tsurutani, B. T., and E. J. Smith (1974), Postmidnight chorus: A substorm phenomenon, J. Geophys. Res., 79, 118-127.

Tsurutani, B. T., and E. J. Smith (1977), Two types of magnetospheric ELF chorus and their substorm dependencies, J. Geophys. Res., 82, 5112-5128.

Wrenn, G. L. (1995), Conclusive evidence for internal dielectric charging anomalies on geosynchronous communications spacecraft, J. Spacecraft and Rockets, 32, 514-520.

Wrenn, G. L., D. J. Rodgers, and K. A. Ryden (2002), A solar cycle of spacecraft anomalies due to internal charging, Ann Geophys., 20, 953-956. 
Figure 1. Average wave electric field spectral intensities for (top) equatorial $\left(-3^{\circ}<\lambda_{m}<3^{o}\right)$ and (bottom) off-equatorial $\left(5^{\circ}<\left|\lambda_{m}\right|<10^{\circ}\right)$ emissions observed outside the plasmasphere as a function of frequency and $L$ for different levels of geomagnetic activity. From left to right the results are for quiet $(A E *<100 \mathrm{nT})$, moderate $(100<A E *<300 \mathrm{nT})$, and active $(A E *>300$ $\mathrm{nT}$ ) conditions. Also shown is the equatorial electron gyrofrequency, $f_{c e}$ (solid line), $0.5 f_{c e}$ (dotted line), the equatorial lower hybrid resonance frequency $f_{L H R}$ (dashed line), and $0.5 f_{L H R}$ (dash-dotted line).

Figure 2. Average wave electric field spectral intensities of (top) equatorial and (bottom) offequatorial emissions observed in the plasmasphere as a function of frequency and $L$ for different levels of geomagnetic activity. From left to right the results are presented for quiet $(A E *<100$ $\mathrm{nT})$, moderate $(100<A E *<300 \mathrm{nT})$, and active $(A E *>300 \mathrm{nT})$ conditions. Also shown is the equatorial electron gyrofrequency, $f_{c e}$ (solid line), $0.5 f_{c e}$ (dotted line), the equatorial lower hybrid resonance frequency $f_{L H R}$ (dashed line), and $0.5 f_{L H R}$ (dash-dotted line).

Figure 3. Average wave electric field intensities of (top) equatorial and (bottom) off-equatorial emissions in the frequency range $0.5 f_{L H R}<f<f_{L H R}$ observed outside the plasmasphere as a function of $L$ and magnetic local time. From left to right the results are presented for quiet $(A E *<100 \mathrm{nT})$, moderate $(100<A E *<300 \mathrm{nT})$, and active $(A E *>300 \mathrm{nT})$ conditions.

Figure 4. Average wave electric field intensities of (top) equatorial and (bottom) off-equatorial emissions in the frequency range $0.5 f_{L H R}<f<f_{L H R}$ observed in the plasmasphere as a function of $L$ and magnetic local time. From left to right the results are presented for quiet $(A E *<100$ $\mathrm{nT})$, moderate $(100<A E *<300 \mathrm{nT})$, and active $(A E *>300 \mathrm{nT})$ conditions. 
Figure 5. Average $16.5 \mathrm{keV}$ proton differential number flux outside the plasmasphere (top panels) and inside the plasmasphere (bottom panels) as a function of $L$ and magnetic local time. From left to right the results are presented for quiet $(A E *<100 \mathrm{nT})$, moderate $(100<A E *<$ $300 \mathrm{nT})$, and active $(A E *>300 \mathrm{nT})$ conditions. The fluxes are shown in the large panels and the corresponding sampling distributions in the small panels.

Figure 6. a). Proton phase space density perpendicular to the magnetic field as a function of energy during the outbound leg of orbit 714 on 14th May 1991 at $L=3.95$ (blue), 4.55 (green) and 5.45 (red). b). Wave spectral intensity as a function of frequency and time from 18:24 UT to 21:00 UT during the outbound leg of orbit 714. The solid white line represents the electron gyrofrequency, $f_{c e}$. The dashed lines from bottom to top represent $f_{L H R}, 0.1 f_{c e}$ and $0.5 f_{c e}$. The first four harmonics of $f_{c e}$ are represented by the dotted lines and the local upper hybrid resonance frequency, $f_{U H R}$, is shown in red.

Figure 7. Number of proton rings (left hand panels), number of proton rings satisfying the criterion $E_{R}>E_{A}$ (central panels), and the equatorial wave intensity (right panels) as a function of $L$ and magnetic local time. The results are displayed for active conditions $(A E *>300 \mathrm{nT})$ for data collected outside the plasmapause (top panels) and inside the plasmapause (bottom panels). The number of samples used to determine the number of events are displayed in the small panels. Figure 8. The proton ring energies, $E_{R}$, and the average Alfvén energy, $\left\langle E_{A}\right\rangle$, as a function of magnetic local time at a). $L=4.05 \pm 0.15$ and b). $L=6.55 \pm 0.15$ during active conditions outside the plasmapause. The proton ring energies, $E_{R}$, and the average Alfvén energy, $E_{A}$, as a function of magnetic local time at c). $L=4.05 \pm 0.15$ and d). $L=6.55 \pm 0.15$ during active conditions inside the plasmapause. The proton ring energy for each event is shown as a cross and the average Alfvén energy is shown by the solid line. 

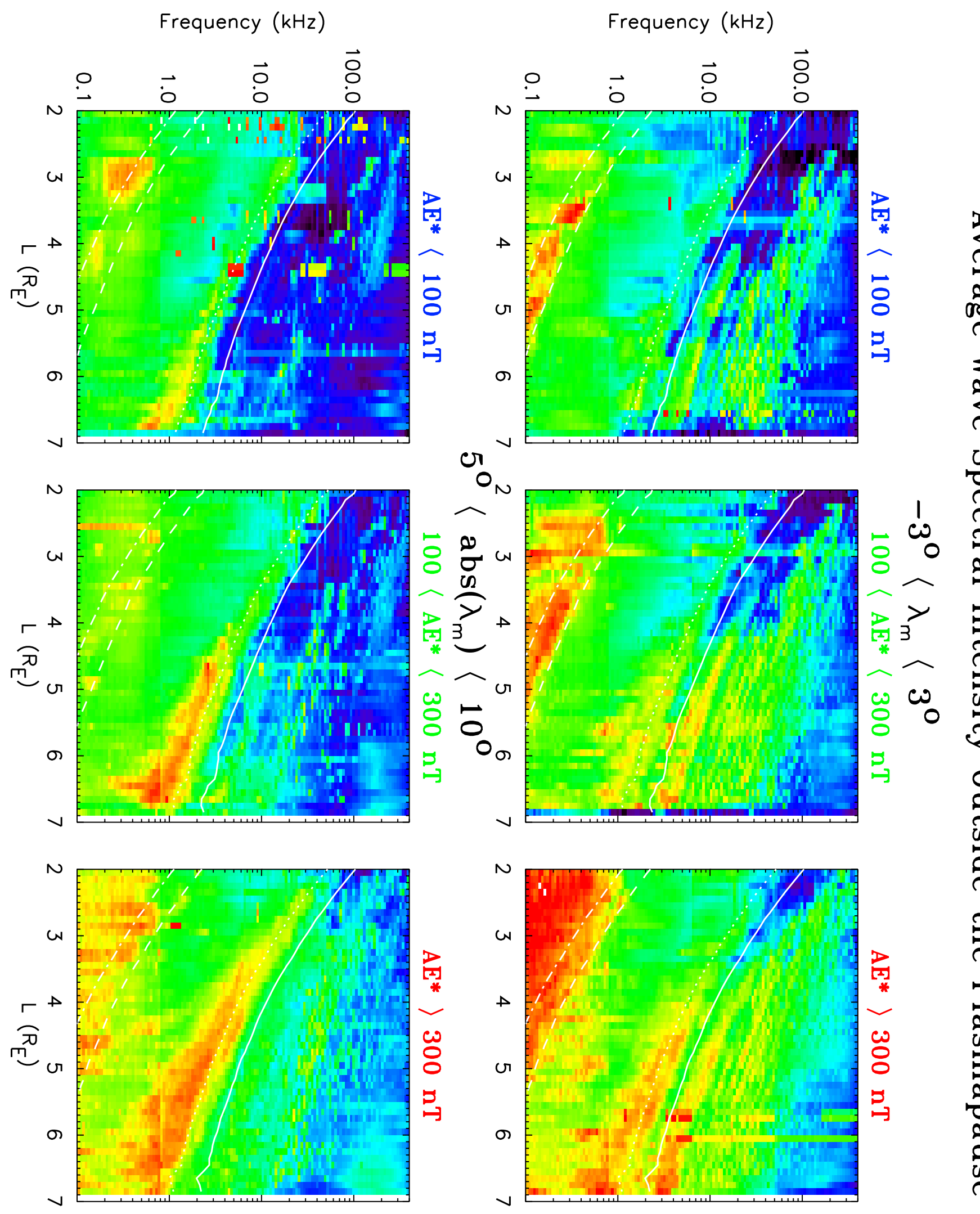

0
0
0
0
0
0
0
0
0
0
0
0
0
0
0
0
0

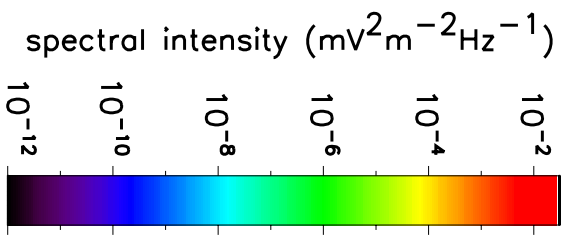

spectral intensity $\left(\mathrm{mV}^{2} \mathrm{~m}^{-2} \mathrm{~Hz}^{-1}\right)$

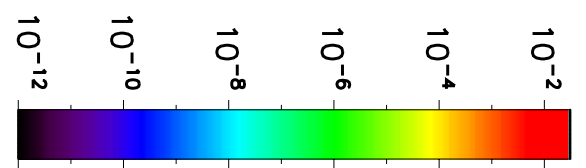



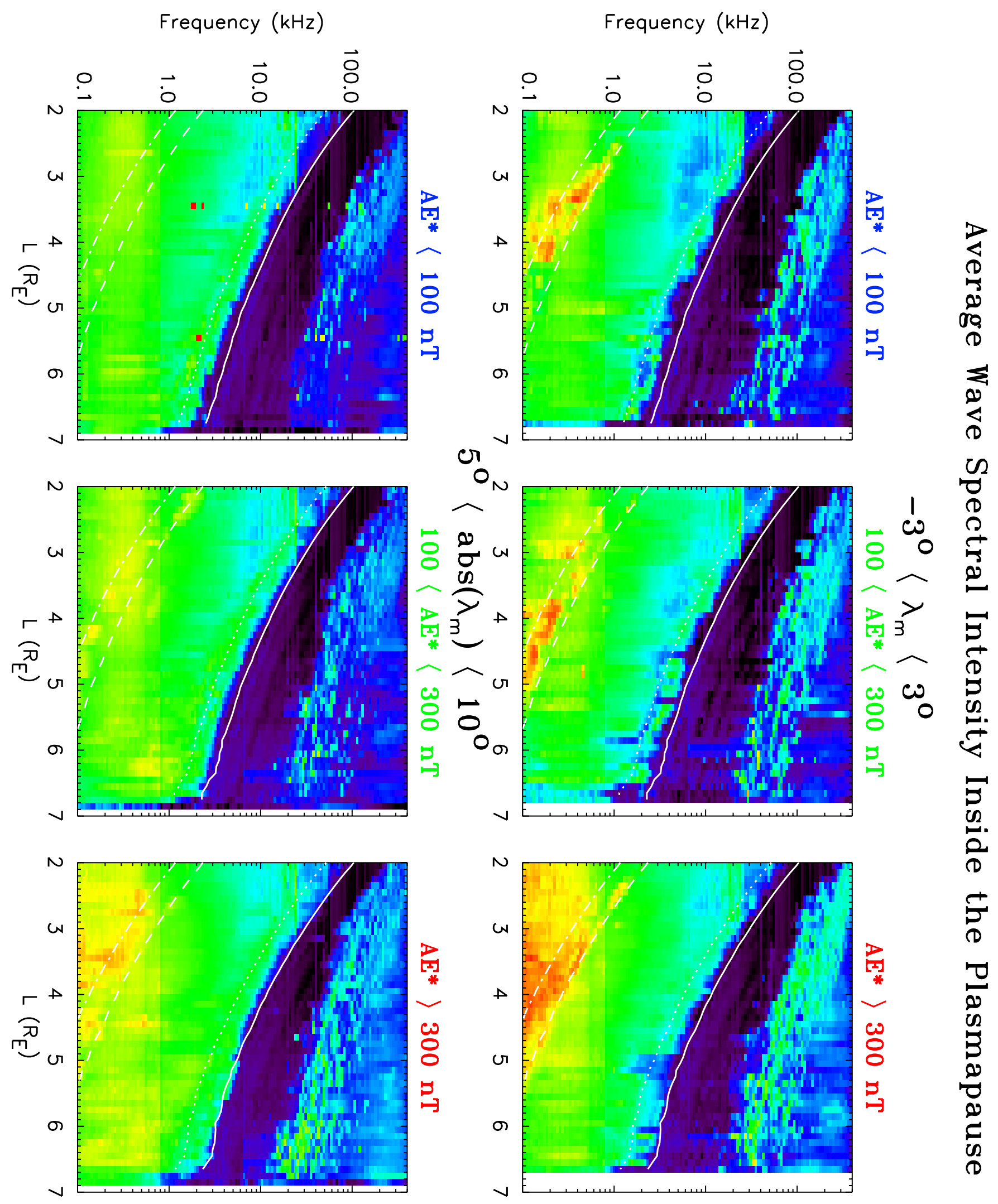

Frequency $(\mathrm{kHz})$
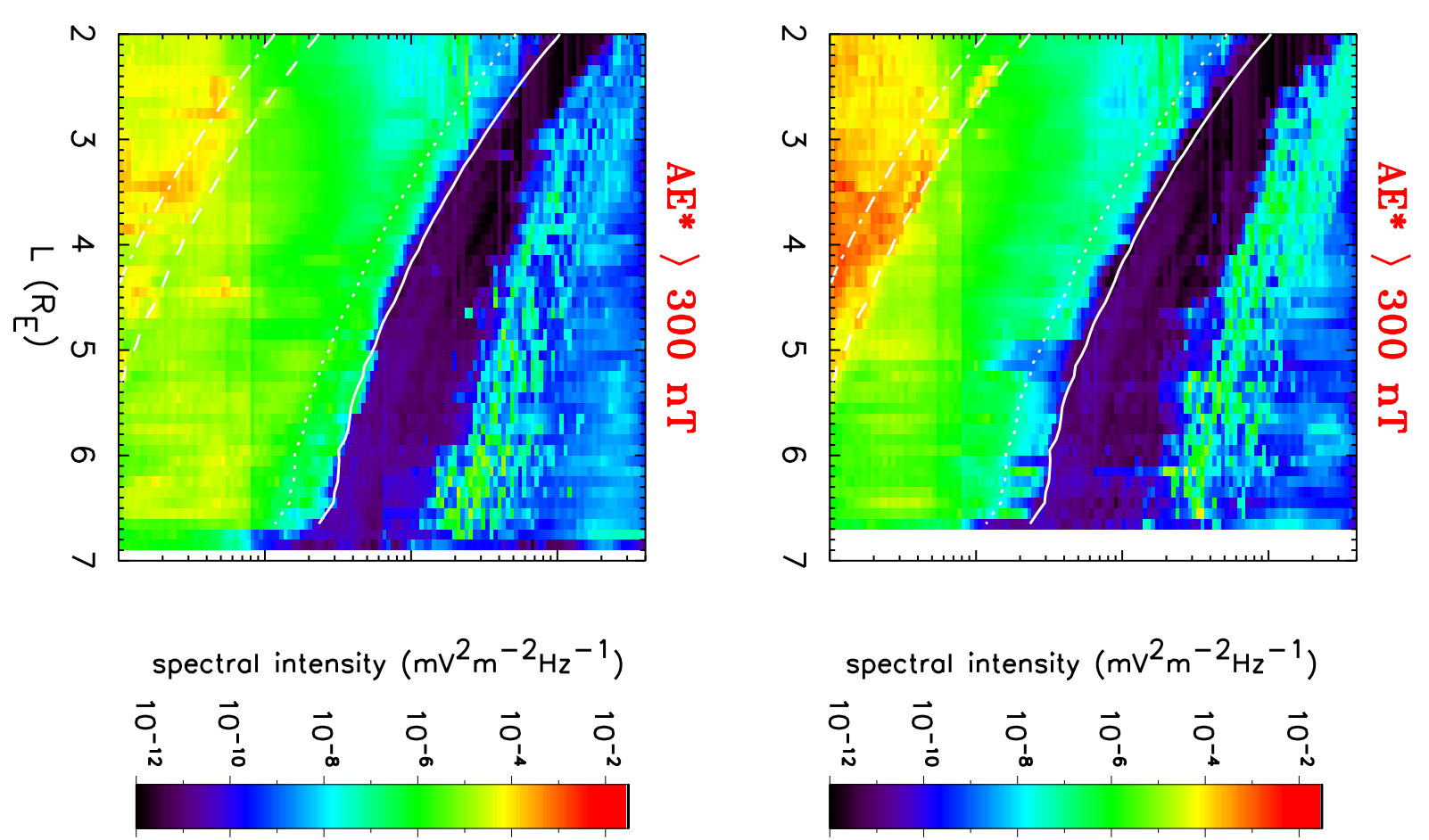
$\stackrel{\infty}{\infty}$
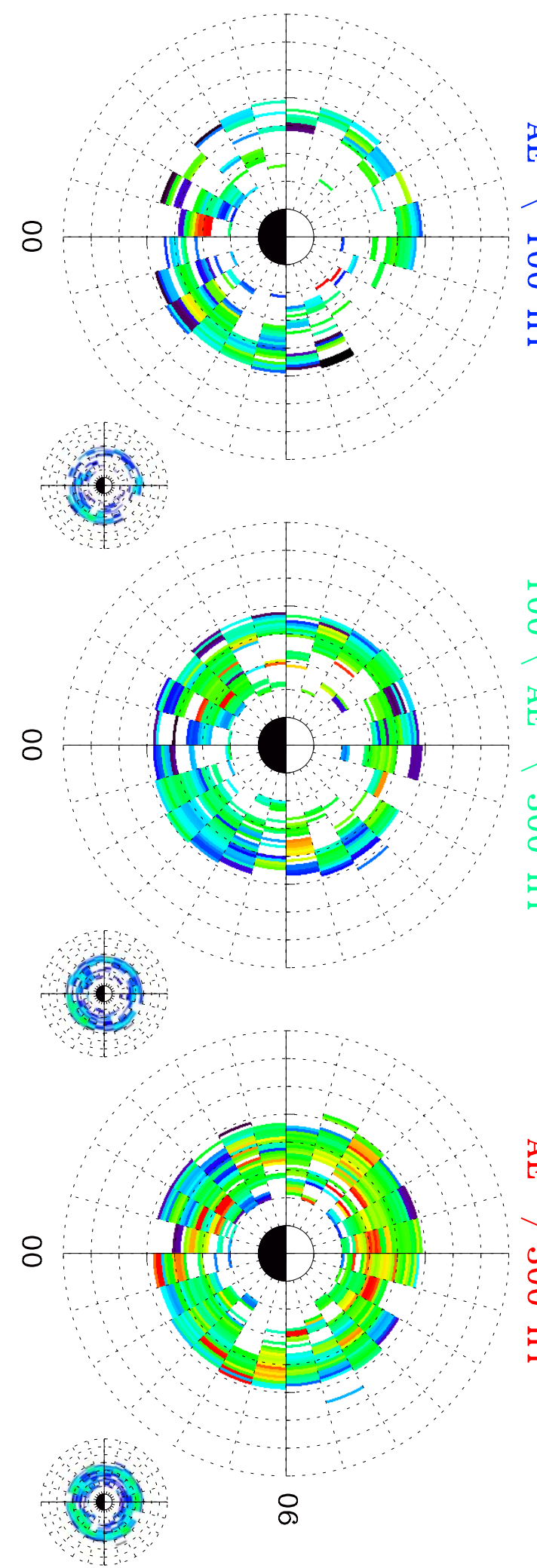

$\stackrel{\infty}{\infty}$

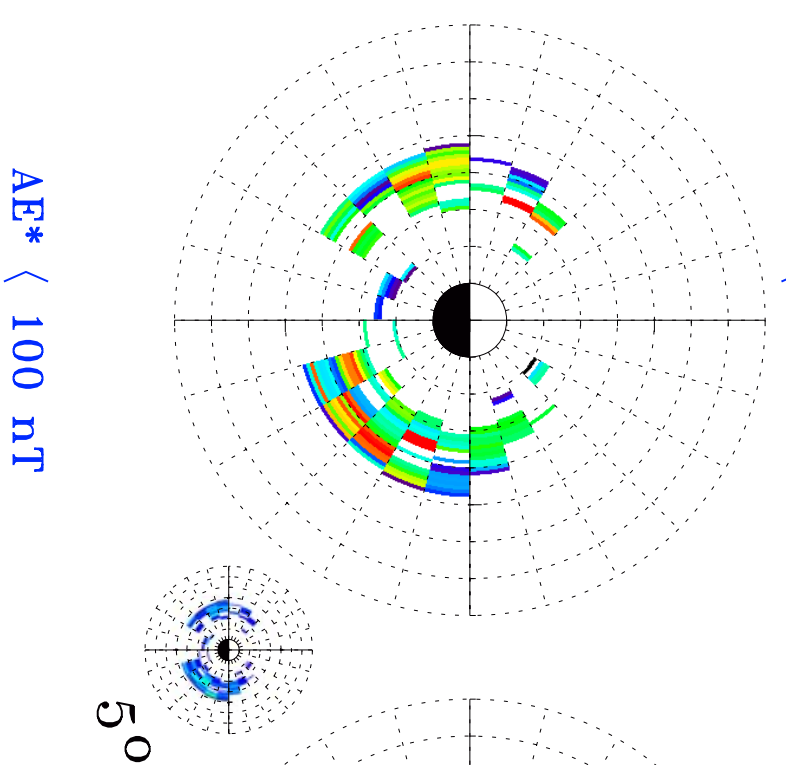

㘴

Ð

回

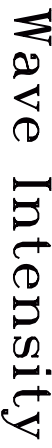

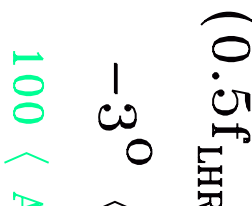

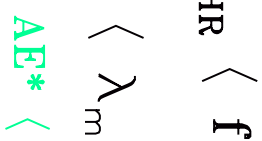
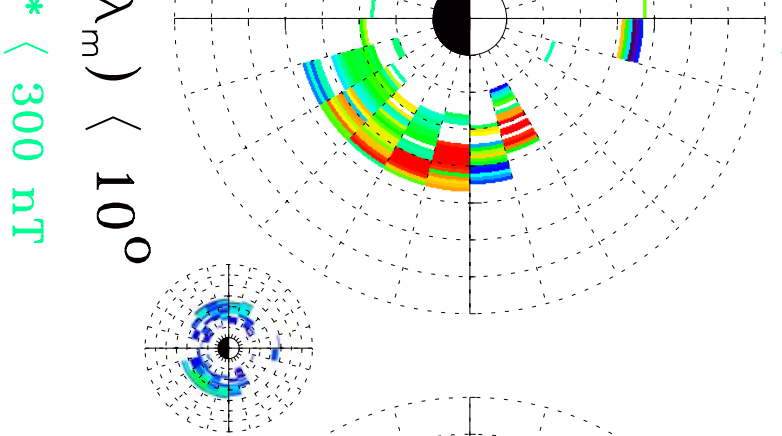

仓̊

$\frac{2}{\stackrel{2}{2}}$
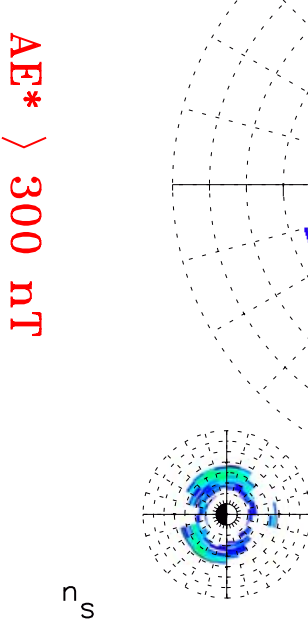

莤

م

7
0
0
0
0
0
0
0
0
0
0

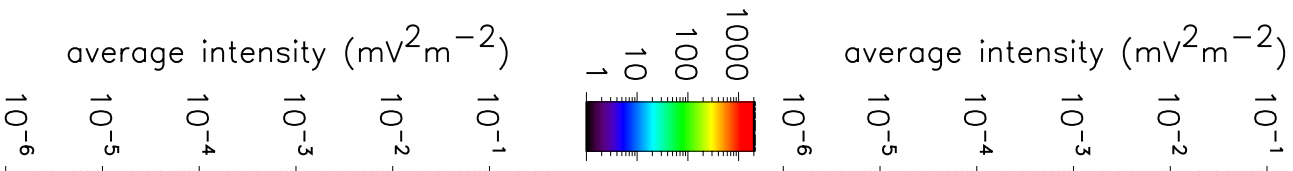


$\stackrel{\infty}{\infty}$
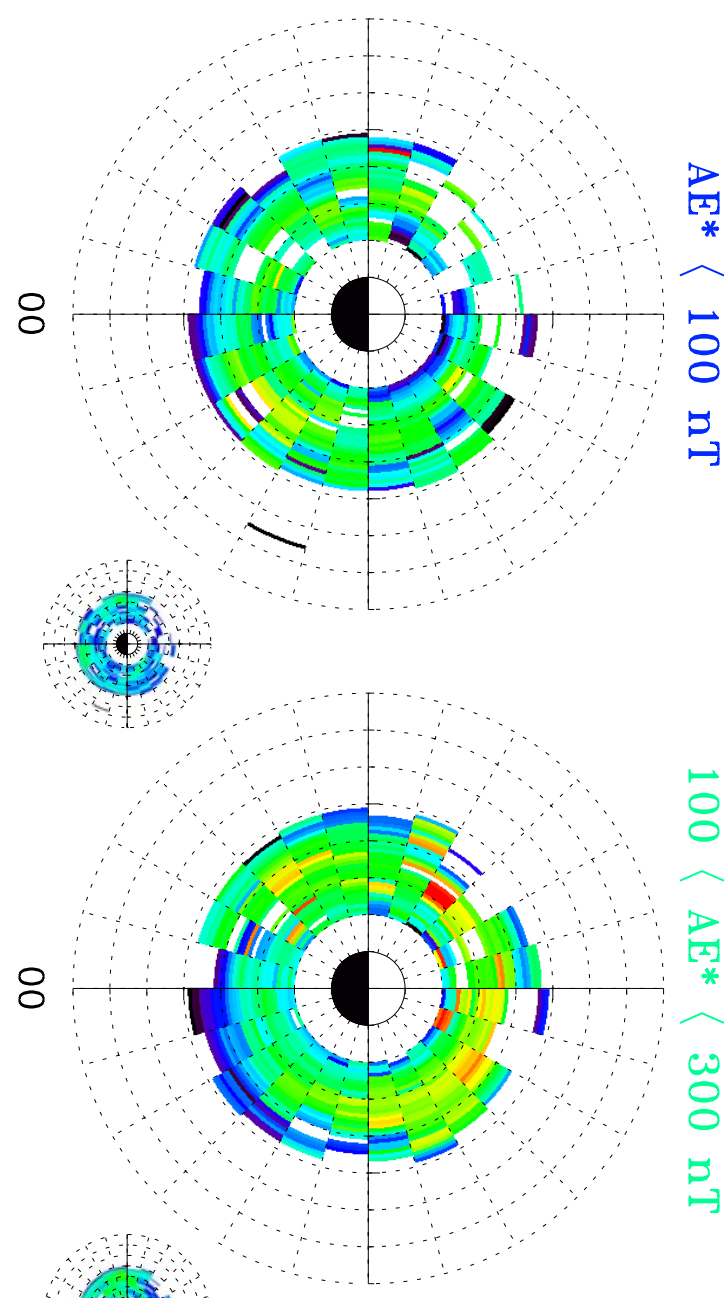

ofots

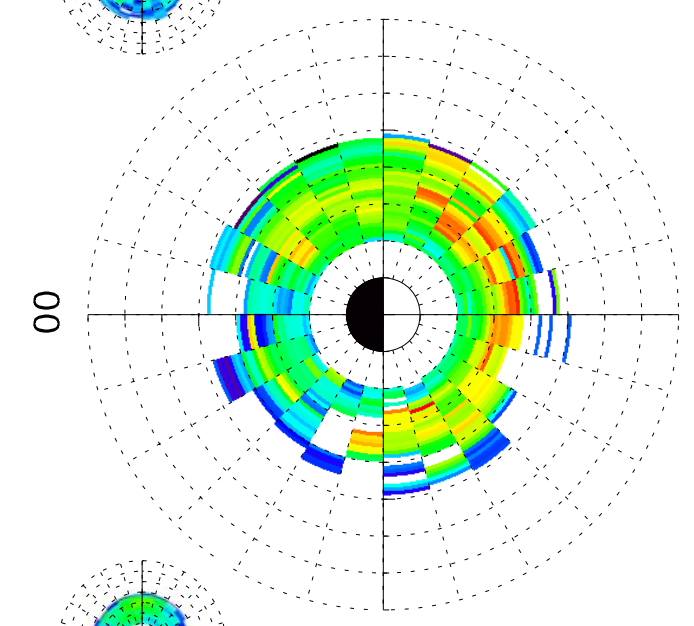

o $\stackrel{\infty}{\infty}$
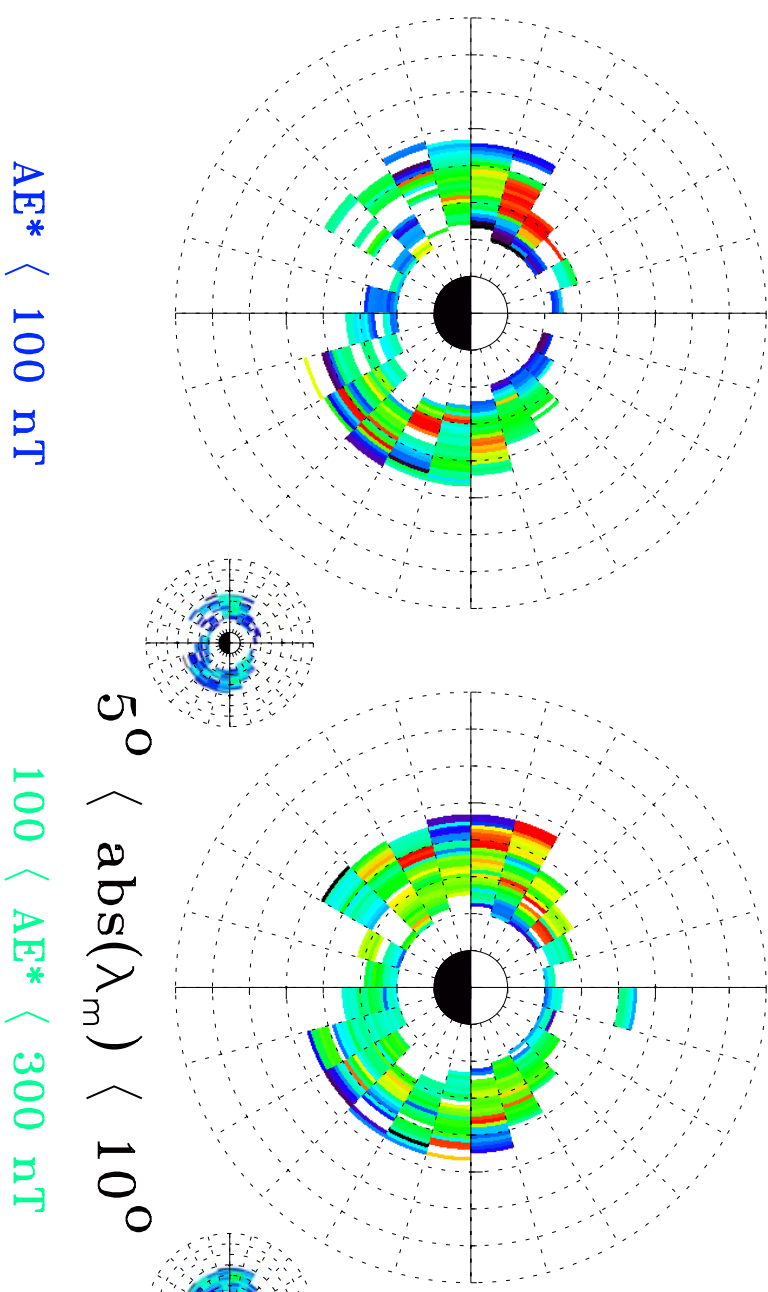

o

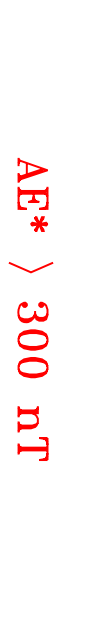

$\underset{*}{*}$

Ю

品

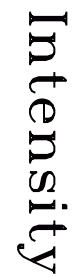

$\begin{array}{lll}- & 1 & 0 \\ 0 & \omega & 0\end{array}$

证要

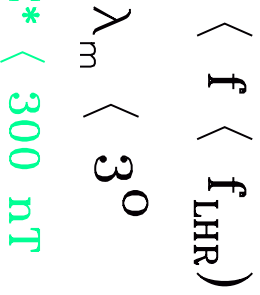

\footnotetext{
average intensity $\left(m v^{2} m^{-2}\right) \quad \rightarrow \vec{\circ} \vec{\circ} \vec{\varnothing} \quad$ average intensity $\left(m v^{2} m^{-2}\right)$
}

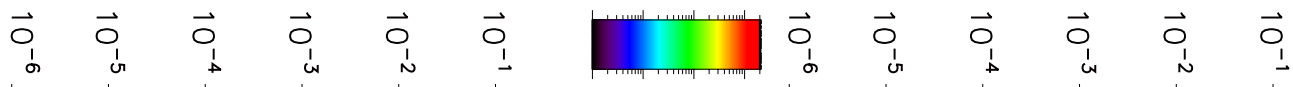




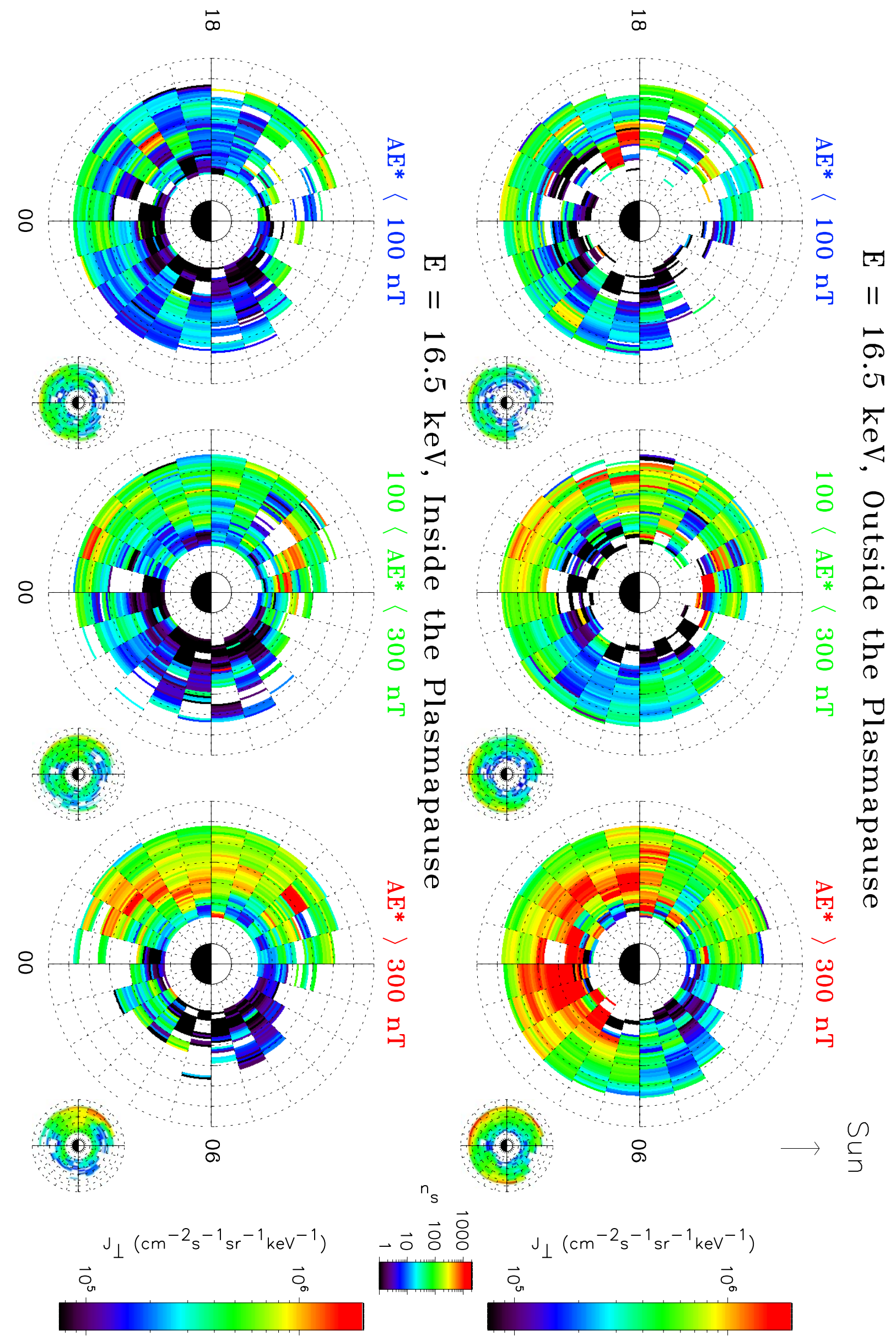



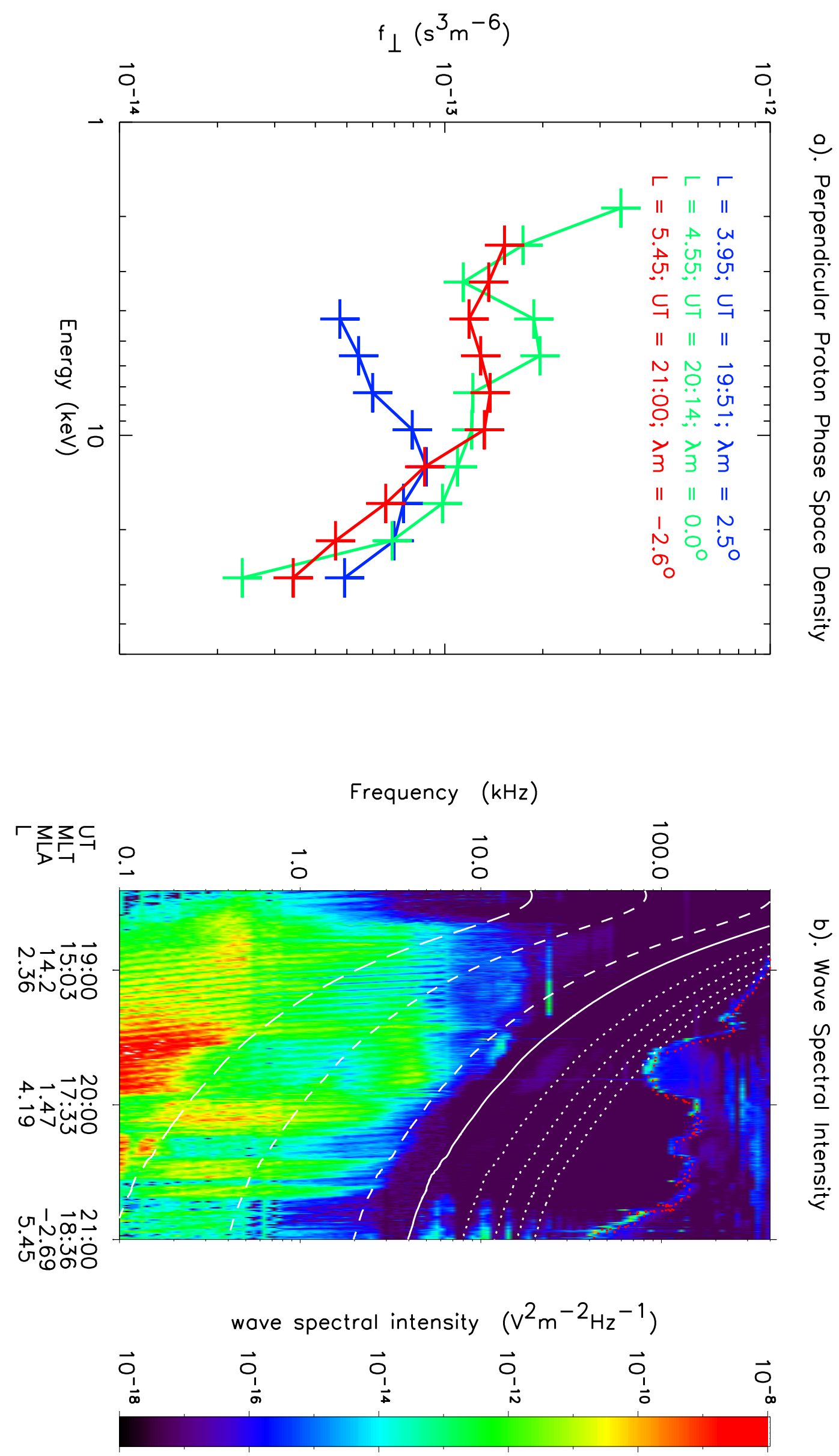

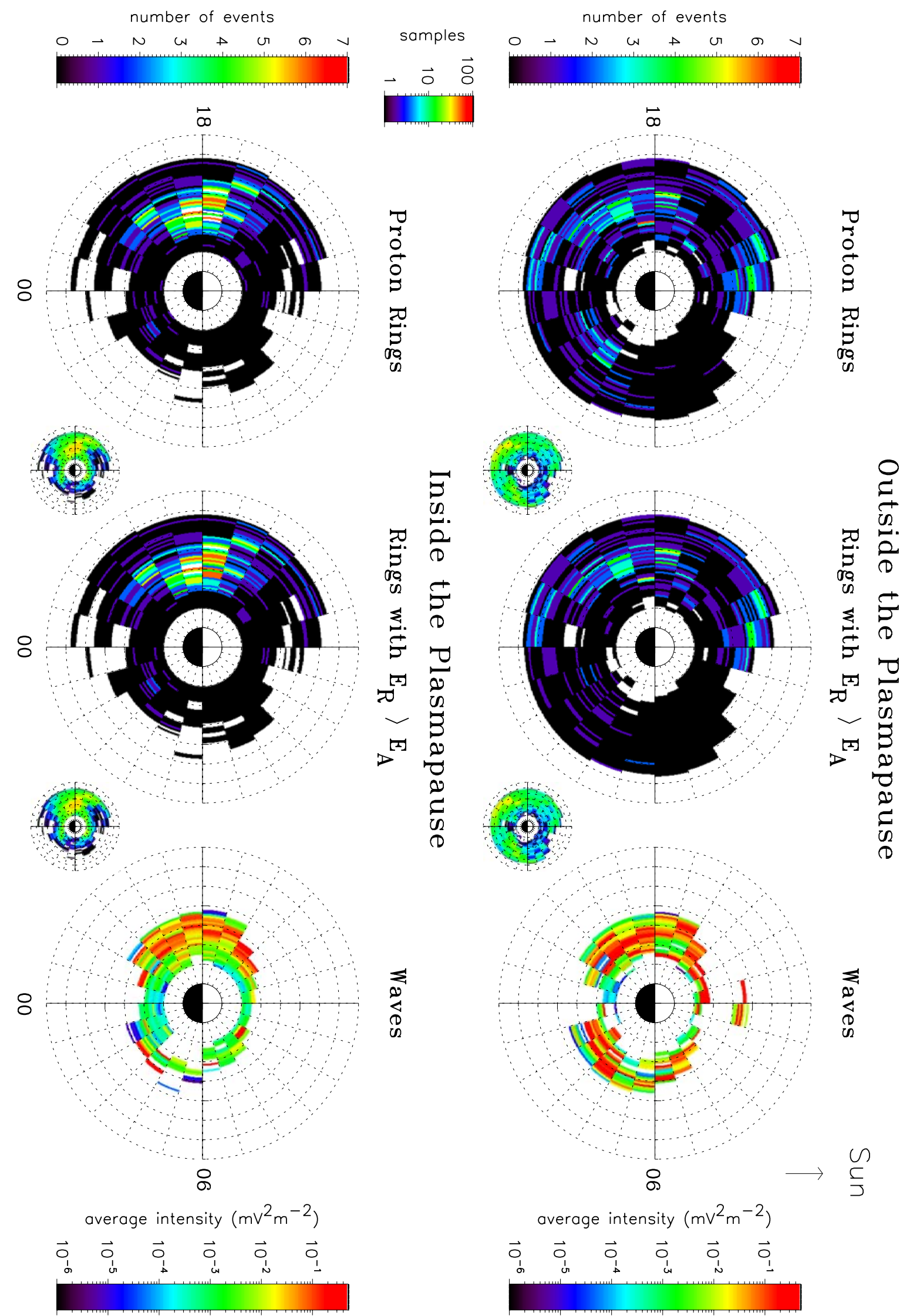


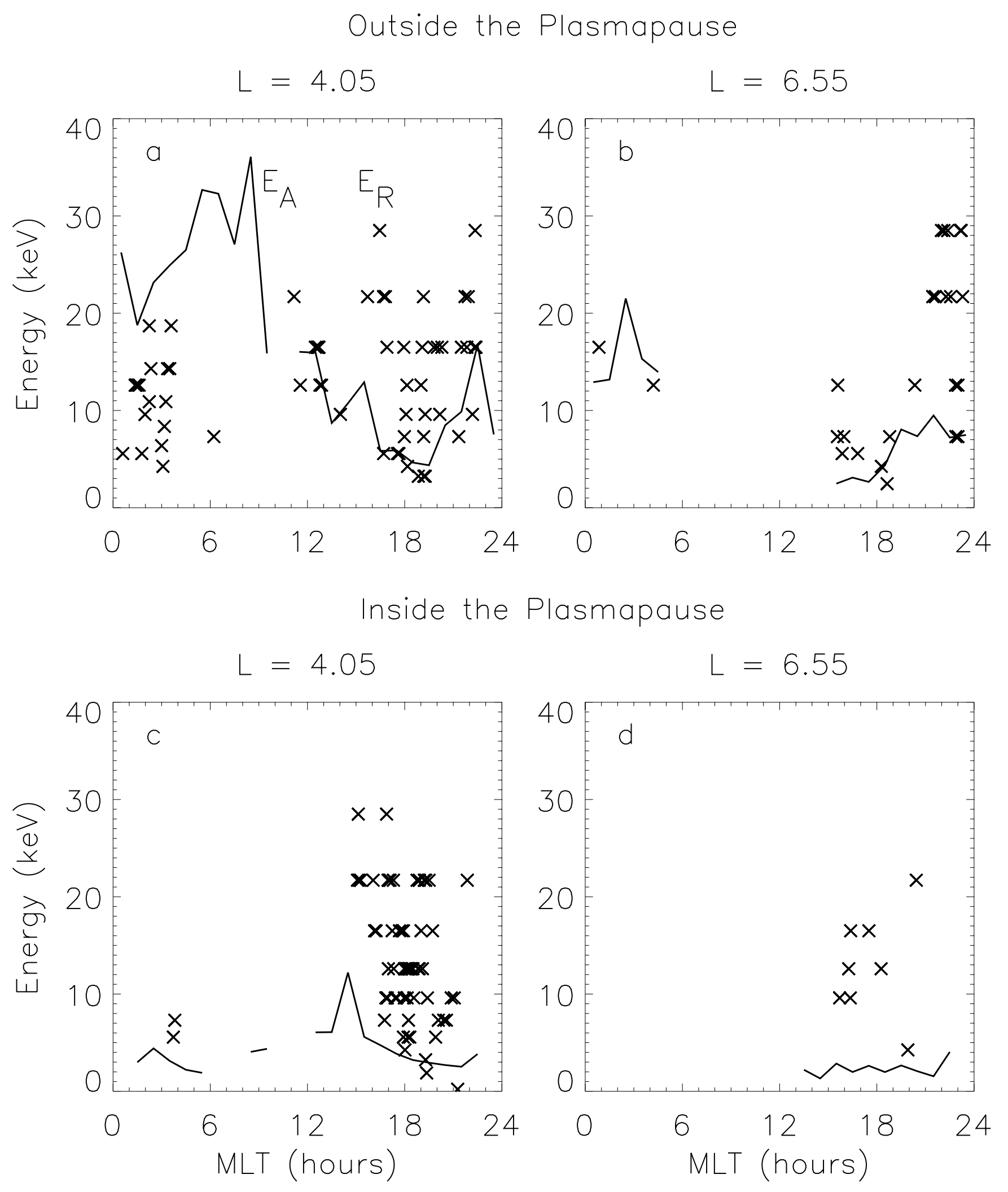

